\title{
Revisão das Propriedades Medicinais de Cajanus cajan na Doença Falciforme
}

CORDOVIL, K..*; COPLE-RODRIGUES, C.S.2; SANTOS, I.N.2, FRANCO, E.D.2; BERTOLUCCI, S.K.V. ${ }^{3}$ 1 Instituto Estadual de Hematologia Arthur Siqueira Cavalcanti (HEMORIO). Rua Frei Caneca, número 8, Rio de Janeiro, RJ, CEP 20.211-030, 2Universidade do Estado do Rio de Janeiro. Rua São Francisco Xavier, 524, Rio de Janeiro, RJ, CEP: 20550-900, 3Universidade Federal de Lavras/Minas Gerais. Caixa Postal 3037, Lavras, MG, CEP: 37.200-000, *Autor para correspondência: karensouz@gmail.com

\begin{abstract}
RESUMO: Este artigo descreve a ocorrência, características botânicas, fitoquímicas e a composição nutricional do feijão guandu [Cajanus cajan (L.) Millsp], e sua relação no processo de inibição da falcização na doença falciforme, um distúrbio genético que acomete as hemácias, gerando hemólise e anemia crônica. Dois constituintes químicos estariam mais relacionados aos efeitos inibitórios na falcização de células falciformes: L-fenilalanina e o ácido $p$-hidroxibenzóico. Estudos químico-biológicos detalhados com o feijão guandu no Brasil poderão esclarecer melhor os mecanismos pelos quais ocorre a inibição da falcização das hemácias e a diminuição do estresse oxidativo, ajudando no tratamento de pessoas com DF.
\end{abstract}

Palavras-chave: propriedades medicinais, cajanus cajan, anemia falciforme.

\begin{abstract}
Review of Medicinal Cajanus cajan of properties in Sickle Cell Disease. This article describes the occurrence, botanical characteristics, phytochemical and nutritional composition of pigeonpea [Cajanus cajan (L.) Millsp], and their relationship in the process inhibition of sickling in sickle cell disease (SCD), a genetic disorder that affects red blood cells, causing hemolysis and chronic anemia. Two chemical components would be related to the inhibitory effect on sickling of sickle cells: the L-phenylalanine and the $p$-hydroxybenzoic acid. In Brazil, detailed studies with pigeonpea chemical-biological may clarify the mechanisms by which the inhibition of sickling of red blood cells occurs, reducing oxidative stress and thus helping treating people affected by this disease.
\end{abstract}

Keywords: medicinal properties, cajanus cajan, sickle cell anemia.

\section{INTRODUÇÃO}

A doença falciforme (DF) é um distúrbio genético decorrente da mutação no gene regulador da síntese da hemoglobina $A$, que origina a hemoglobina mutante S (Jesus, 2010). As manifestações clínicas comuns na DF, devem-se a dois fenômenos principais: a oclusão vascular pelos glóbulos vermelhos e a hemólise crônica, levando a lesão progressiva dos tecidos e órgãos (Emokpae et al., 2010; Braga, 2007).

No Brasil, a Portaria n॰ 822/01 do Ministério da Saúde incluiu a DF no Programa Nacional de Triagem Neonatal (PNTN), permitindo assim o diagnóstico no nascimento, afim de reduzir a morbimortalidade da DF (Brasil, 2001). Dados epidemiológicos do PNTN revelam a elevada proporção de nascidos vivos com a DF nos estados da Bahia (1:650), Minas Gerais (1:1400) e do Rio de Janeiro (1:1200) (Jesus, 2010). Portanto, a importante taxa de prevalência e de morbidade no território brasileiro, torna a DF um sério problema de saúde (Lobo, 2010; Modell \& Darlison, 2008;). O tratamento da DF inclui a suplementação de ácido fólico, analgésicos, anti-inflamatórios, hidroxiuréia (para pacientes que se adequem ao protocolo), hidratação venosa nas crises álgicas, realização de transfusão sanguínea, o uso profilático de antibióticos (em menores de 5 anos de idade), imunizações periódicas e do tratamento específico das complicações secundárias à doença (Batista \& Andrade, 2008; Bruniera, 2007; Braga, 2007). Há também uma ênfase na educação em saúde que estimula o autocuidado pelos pacientes e seus acompanhantes/responsáveis (Araujo, 2007). Todas essas medidas visam prevenir os eventos agudos e melhorar o prognóstico e a qualidade de vida das pessoas com DF. 
Práticas integrativas e complementares em saúde são regulamentadas como recursos terapêuticos, principalmente com o uso de plantas medicinais associadas à alimentação (Silva \& Oliveira, 2013; Brasil, 2006). Alguns fitoquímicos presentes nestas plantas podem intervir de modo benéfico na saúde humana, protegendo ou ajudando no tratamento de diversas doenças (Ferreira et al., 2014; Oliveira et al., 2014).

Alguns princípios ativos de plantas medicinais vêm sendo estudados na DF para que possam proporcionar maior estabilidade à hemácia, atuar como agentes anti-falcização e melhorar o prognóstico e a saúde dos pacientes (Oniyangi \& Cohall, 2013; Afolabi et al., 2012; Segal et al., 2004; Zemel et al., 2002; Muskiet et al., 1991).

Alguns estudos científicos têm apontado que o feijão guandu (Cajanus cajan (L.) Millsp Fabaceae) seja um importante agente medicinal que atue, minimizando algumas complicações da DF através da inibição da falcização (Oniyangi \& Cohall, 2013; Akinsulie et al., 2005; Ekeke \& Shode, 1985).

Nesse sentido, o presente trabalho tem por objetivo realizar uma revisão de estudos científicos no emprego do feijão guandu, englobando trabalhos in vitro, in vivo, estudos clínicos, bem como de substâncias isoladas desta espécie vegetal que possam atuar ou influenciar na inibição da falcização na DF.

\section{MATERIAL E MÉTODO}

Foi realizado um levantamento bibliográfico entre os anos de 2008 e 2014 utilizando- se bases de dados Latino-americanas e Internacionais: Biblioteca Virtual em Saúde (BVS), Entrez Global Query Cross-Database Search System (ENTREZ) e British Library Direct (BLD), e as ferramentas de pesquisa Pubmed, Scielo e Google acadêmico. Para a busca foram utilizados o operador boleano "OU"/"OR" nos 2 grupos de palavras-chave separadamente: (cajanus cajan, pigeon pea) e (antisickling, sickle cell anemia e sickle cell disease). Após isso, utilizou-se o operador boleano "E"/ "AND" para obter a intersecção entre os 2 grupos de palavras-chave mencionados acima.

\section{Processo de Falcização das Hemácias}

Os genes que codificam as subunidades da hemoglobina estão abundantemente presentes e apresentam alta similaridade em sua estrutura genômica (três éxons e dois íntrons) ao longo das linhagens dos vertebrados (Quinn et al., 2010).

Em humanos, por conta de mutações espontâneas, surgem outras hemoglobinas variantes que podem ser diferentes por exemplo, do ponto de vista estrutural, no caso de uma alteração no nível de seqüência de aminoácidos (como ocorre na DF) ou no caso em que ocorre uma diminuição ou supressão da produção de uma cadeia de globina (no caso das talassemias). Estas alterações dão origem, portanto às hemoglobinopatias (Hoffbrand \& Moss, 2013; Modell \& Darlison, 2008).

$\mathrm{Na}$ DF, portanto, ocorre a formação de uma hemoglobina denominada $\mathrm{Hb} \mathrm{S}(\alpha 2 \mathrm{~A} \beta 2 \mathrm{~S})$ devido a uma mutação no gene que sintetiza a cadeia $\beta$ da hemoglobina, através da troca da base nitrogenada adenina do códon GAG pela timina (GTG) (Neto \& Pitombeira, 2003; Naoum, 2000).

Anemia falciforme $(A F)$ foi a primeira doença de base molecular que demonstrou que a hemoglobina destes pacientes tinha excesso de carga positiva em comparação com hemoglobinas de adultos saudáveis (Galkin et al., 2007; Zago \& Pinto, 2007).

Por conta dos pontos isoelétricos dos aminoácidos serem diferentes (glut (-) = 5,97 e Val carga $(0)=2,77$ ) ocorre um desequilíbrio implicando na perda de cargas negativas da $\mathrm{Hb} \mathrm{S}$ em relação à $\mathrm{Hb} \mathrm{A}$. Tudo isso acarreta sérias alterações na estrutura física e fisiológica prejudicando assim sua funcionalidade, principalmente ao que se refere ao carregamento de oxigênio pela corrente sanguínea (Naoum, 2000).

Em situações de ausência ou diminuição da tensão de oxigênio, a oxi-HB $S$ perde $\mathrm{O}_{2}$ e se transforma em deoxi-Hb $\mathrm{S}$, formando pontes de hidrogênio entre os aminoácidos valina da posição $\mathrm{n} 1$ da globina beta $S$ (posição normal) e a valina mutante da mesma globina (Neto \& Pitombeira, 2003; Naoum, 2002; Brasil, 2006).

A presença das pontes de hidrogênio gera uma mudança na estrutura da globina, o qual gera uma aproximação e permite contatos intermoleculares entre aminoácidos das hemoblobinas S (GLU121 $\rightarrow$ GLY16; ASP73 $\rightarrow$ THR4, entre outros) (Naoum, 2002; Neto \& Pitombeira, 2003).

Além disso, através das interações hidrofóbicas entre valina ( $\beta-6)$ com a concavidade hidrofóbica formada principalmente por LEU $(\beta-88)$ e $\mathrm{FEN}(\beta-85)$, ocorre a formação de polímeros de $\mathrm{HbS}$ (Neto \& Pitombeira, 2003; Naoum, 2002).

A polimerização portanto, é a formação de fibras de $\mathrm{Hb} \mathrm{S}$, que se assemelha a uma primeira fase de transição, semelhantes a uma transformação gás-sólido (Galkin et al., 2007). Quando há elevado grau de polimerização na desoxi-HbS, a mesma apresenta um comportamento semelhante a um gel característicos de polímeros (Rotter et al., 2011; Galkin et al., 2007).

Dentre os fatores que favorecem a polimerização da $\mathrm{Hb} \mathrm{S}$ estão: queda do $\mathrm{pH}$ sanguíneo, aumento da concentração de 2,3 di- 
fosfoglicerato, saturação de oxigênio insuficiente, perda de potássio e água (Naoum, 2002; Brasil,2006; Neto \& Pitombeira, 2003).

A polimerização da HbS inicia-se através de um fenômeno chamado de nucleação, do qual um certo número de moléculas se juntam dentro de um embrião da nova fase (lqbal et al., 2013; Li et al.,2011; Rotter et al.,2011; Galkin et al., 2007).

A nucleação é seguida pelo crescimento de fibras iniciais e sua ramificação, devido à nucleação secundária de novas fibras em cima das existentes, como se fosse uma dupla nucleação (Li et al.,2011; Rotter et al., 2011; Usunova, 2010; Galkin et al., 2007).

A hemoglobina $S$ forma 14 membros de fibras quando está no estado desoxigenado em que possui conformação em T (Galkin et al., 2007). Entre as fibras ocorrem contatos hidrofóbicos que são formados entre a valina da molécula $\mathrm{Hb} \mathrm{S}$ e a alanina, fenilalanina e leucina a partir de uma molécula de $\mathrm{Hb}$ S adjacente (Galkin et al., 2007).

Estes polímeros em seguida formam fibras de desóxi-hemoglobinas enoveladas que progride através da produção de mais fibras alongadas, o que no final alteram a estrutura da hemácia por precipitação das globinas, formação dos corpos de Heinz, e finaliza com a formação de uma hemácia em forma de foice, em vez de discoide (Naoum, 2002; Brasil,2006; Neto \& Pitombeira, 2003).

A afinidade do oxigênio pela hemoglobina, a concentração de $\mathrm{Hb} \mathrm{S}$, desidratação, concentração mínima de gelificação, acidose e febre são eventos determinantes, que influenciam diretamente no processo de falcização (Godwin \& Baysinger, 1983) .

\section{Agentes inibidores da falcização}

No tratamento coadjuvante da DF, buscase compostos (bioativos ou químicos) que possam oferecer mais estabilidade à hemácia, atuando como um agente antifalcização, a fim de melhorar o prognóstico e a saúde dos pacientes (Nnamani et al., 2008; Segal et al., 2004; Zemel et al., 2002; Muskiet et al., 1991).

A maneira com que cada um desses compostos químicos/bioativos interage com componentes presentes na hemácia é específica e variada (Dash et al., 2013; Nnamani et al., 2008; Godwin \& Baysinger, 1983). Em geral, estes agentes são divididos de acordo com o tipo de interação que possuem com a hemoglobina ou o tipo de mecanismo de ação (Tabela 1).

Agentes inibidores da falcização devem ser de fácil administração, preferencialmente oral, e com adequada absorção, capazes de entrar nas hemácias, reagir com a hemoglobina ou com a membrana de tal forma que a falcização seja impedida, sem causar toxicidade ou efeitos secundários hematológicos adversos, como o aumento da afinidade do oxigênio ou a elevação da hemólise (Dash et al., 2013; Akinsulie et al., 2005; Park et al., 2003).

\section{Ocorrência e Características Botânicas de Cajanus Cajan \\ É uma cultura importante para diversos} países dos trópicos e subtrópicos, principalmente os países asiáticos e africanos (Mizubuti et al., 2000; Seno et al.,1996). A sua origem ainda é motivo de controvérsia, divergindo entre o Continente Africano e a Índia. Foi introduzida no Brasil provavelmente pela rota dos escravos, nos navios negreiros procedentes da África, tornando-se largamente distribuída e seminaturalizada na região tropical (Azevedo et al., 2007).

No Brasil, o feijão guandu também pode ser denominado de feijão-andu, guandeiro, guando ou andu (Mizubuti et al., 2000). É uma planta perene, de vida curta, frequentemente cultivada para produção de grãos, pois suas sementes exalbuminosas são utilizadas na alimentação humana ou animal (Azevedo et al., 2007).

A planta possui flor com estrutura característica de autofecundação, contudo a presença de agentes polinizadores (abelhas) aumenta em $97,9 \%$ a produção de suas vagens e sementes (Cruz-Garcia \& Price, 2011).

O crescimento pode se apresentar semiprostrado ou ereto e a altura, mesmo sendo desejável que seja baixa pode atingir em algumas linhagens pode ser igual ou superior a 2 metros (Gody et al., 2004). Logo, por consequência o número de ramos primários tende a ser maior. A cor do caule pode ter tons de verde a arroxeados e sua espessura pode variar (Provazi et al., 2007). Tem folíolo em forma elíptica estreita e a cor básica das flores matiza em tons de amarelo (Godoy et al., 2004; Provazi et al.,2007).

Em relação ao padrão de florescimento sabe-se que o florescimento de padrão determinado é mais vantajoso do ponto de vista de produção de sementes. A cor da vagem difere de verde a púrpura (sem maturação) ou palha e violeta escura (quando maduras) sendo que sua forma pode ser cilíndrica a achatadas e estreitas. Em relação à semente pode ser do padrão manchado ou pintado e machado, com uma variedade de cores (Godoy et al., 2004; Provazi et al., 2007).

\section{Fitoquímica e Composição Nutricional do Feijão Guandu \\ Em toda planta há fitoquímicos} principalmente alcalóides, saponinas e flavonóides (Das et al., 2013; Nwodo et al., 2011; Chougule et al., 2003; Giri et al., 1998). Na raiz estão 
TABELA 1. Resumo dos principais tipos de agentes anti-falcização.

\begin{tabular}{|c|c|c|}
\hline Tipo de inibição & Mecanismo de ação & Agentes \\
\hline \multirow{8}{*}{ Covalente } & \multirow{8}{*}{$\begin{array}{l}\text { Reagem com proteínas formando ligações } \\
\text { permanentes fortes } \\
\text { afetam a membrana celular }\end{array}$} & Cianeto (tóxico) \\
\hline & & Mostarda nitrogenada \\
\hline & & Imidoesteres \\
\hline & & Suphidrila \\
\hline & & Gliceraldeido \\
\hline & & Bisfumarato \\
\hline & & Piridoxal \\
\hline & & Cistamina \\
\hline \multirow{4}{*}{ Não covalentes } & \multirow{4}{*}{$\begin{array}{l}\text { Formam ligações fracas com a hemoglobina (iônicas } \\
\text { ou hidrofóbicas) }\end{array}$} & Oligopeptídeos \\
\hline & & Aminoácidos \\
\hline & & Uréia de alquilas (tóxico) \\
\hline & & Etanol (hepatotóxico) \\
\hline \multirow{4}{*}{$\begin{array}{l}\text { Ativados na } \\
\text { Membrana celular }\end{array}$} & \multirow{4}{*}{ Atuam sobre a membrana celular diretamente } & Zinco \\
\hline & & Extrato de Fagara zanthoxyloides \\
\hline & & Procaína \\
\hline & & Vitamina $\mathrm{E}$ \\
\hline $\begin{array}{l}\text { Diminuição na } \\
\text { concentração } \\
\text { intracelular de Hb S }\end{array}$ & Induzem a turgência celular e diluição da Hb S & $\begin{array}{l}\text { DDAVP (vasopressina sintética) } \\
\text { Dextrose }\end{array}$ \\
\hline
\end{tabular}

Fontes: Dash et al., 2013; Park et al., 2003; Ouattara et al.,2009; Mehanna, 2001; Godwin \& Baysinger, 1983; Abu et al., 1981 Franklin \& Huehns, 1980.

presentes a cajaflavanona, a cajaisoflavonona, a 2'-O-metil-cajanona, a cajaquinona, a trihidróxiisoflavonas, a a e $\beta$-amirina, a genisteína e o lupeol. $\mathrm{Na}$ casca da raiz há isogenisteína-7-Oglicosídeo; nas sementes encontra-se o ácido aspártico, a cajanina e a concajanina; nas folhas o $\beta$-sitosterol e o estigmasterol e, em toda planta, há a 2-hidroxigenisteína, a cajanona e a ferreirina, entre outros (Nwodo et al., 2011; Das et al., 2013; Chougule et al., 2003; Giri et al., 1998).

Em relação a composição nutricional sabese que mais de $50 \%$ da massa seca do feijão guandu é constituída de carboidratos, dentre estes xilose, glicose e galactose (Seno et al.,1996; Menezes et al., 1997). Já o teor de proteínas totais varia entre 19 a $24 \%$ dependendo da época, do local de plantio e de cultivares (Azevedo, 2007). De acordo com Canniatti-Brazaca et al. (1996) os cultivares L04, L12 e L36 do feijão guandu são os que podem ser introduzidos à alimentação humana, pois tem elevada produção com curto período de maturação dos grãos, além de requerer tempo de cocção muito próximo ao do feijão comum (Phaseolus vulgaris) e maior conteúdo protéico.

Quanto ao teor de aminoácidos, Teixeira et al. (1985) demonstraram que o feijão guandu apresentou elevados teores de lisina $(11,51 \%$ a $12,77 \%)$ e de fenilalanina $(10,75 \%$ a $12,31 \%)$ na fração proteica, no entanto os aminoácidos sulfurados, cistina e metionina, apresentaram valores muito baixos $(\leq 0,58 \%)$. Destaca-se ainda em sua composição nutricional, a baixa quantidade de lipídios que varia entre $1,1 \%$ a $1,4 \%$ da massa seca (Azevedo, 2007).

Em relação aos demais nutrientes, por cada $100 \mathrm{~g}$ de semente, há importante presença de potássio $(1.215 \mathrm{mg})$, de cálcio $(129 \mathrm{mg})$, de magnésio (166 mg) e de fósforo $(269 \mathrm{mg}$ ) (Taco, 2011; USDA, 2008).

\section{Feijão Guandu e Doença Falciforme}

O processo de falcização da hemácia inicia-se com a polimerização das moléculas de hemoglobina $\mathrm{S}(\mathrm{Hb} \mathrm{S})$, devido a interação do resíduo hidrofóbico $\beta$ Val6 com $\beta$ Phe85 e $\beta$ Leu88 do grupo heme de outra molécula de HbS (Santos, 2012). Com a progressão da polimerização ocorre à adição sucessivas de moléculas $\mathrm{HbS}$ à medida que o percentual de saturação de oxigênio da hemoglobina diminui, com isso agregados maiores se alinham em fibras paralelas formando um gel de cristais líquidos chamados tactóides, que promove rigideze distorção das hemácias desoxigenadas implicando no surgimento de crise álgica (Santos, 2012).

Aassociação de C. cajan e doença falciforme foi demonstrada pela primeira vez por Ekeke \& 
Shode (1985), que realizaram um ensaio in vitro com sangue de indivíduos com anemia falciforme (HbSS), quimicamente falcizado com metabissulfito de sódio. Os pesquisadores observaram uma reversão da falcização no sangue de pacientes submetidos ao extrato de guandu.

Ao longo das décadas, as propriedades antifalcização do extrato das sementes de guandu tem sido atribuída principalmente a L-fenilalanina, o qual foi indicada como responsável $70 \%$ da propriedade antifalcização no extrato aquoso das sementes de guandu (Uwakwe et al., 1996).

A L-fenilalanina tem sido apontada também como uma boa precursora de ácidos fenólicos. $\mathrm{O}$ ácido hidroxibenzóico por exemplo, está presente nos extratos $C$. cajan e pode inibir a formação ou até mesmo reverter a hemácia falcizadas (Ouattara et al., 2004; Rossato et al., 2009; Vieira, 2010). Alguns estudos apontam uma inibição mais eficientes da fenilalanina e de ácido hidroxibenzóico, sugerindo que uma atuação sinérgica entre eles poderia aumentar o efeito inibitório da falcização (Ekeke \& Shode, 1988; Iwu et al., 1988; Akojie \& Fung, 1992; Chougule et al., 2003; Akinsulie et al., 2005).

Outros compostos presentes no guandu, como a cajaminose, tem sido relacionada com melhora da afinidade de $\mathrm{Hb} \mathrm{S}$ com o oxigênio e com o retardo da falcização, porém foram pouco estudados (Ekeke \& Shode, 1988; Iwu et al., 1988; Akojie \& Fung, 1992; Chougule et al., 2003; Akinsulie et al., 2005).

Acredita-se que a região da hemoglobina onde os agentes antifalcização atuam, se localiza próximo ao heme das cadeias alfa e beta da desoxihemoglobina S (Seno et al., 1996; Uwakwe \& Ekeke,1996).

Em 2005, um estudo clínico realizado com um suplemento a base de feijão guandu (Ciklavit ${ }^{\circledR}$ ) oferecido à crianças e adolescentes observou queda significante no número de crises álgicas no grupo caso versus o controle $(p<0,05)$ e nos casos de hepatomegalia, inicialmente de $55,3 \%$ para $33,3 \%$ $(p<0,03)$ ao final de seis meses (Akinsulie et al., 2005).

Em 2010, um estudo confirmou o uso do suplemento nutricional Ciklavit ${ }^{\circledR}$ na produção da redução significativa do número de células falciformes em amostras de sangue tanto de pessoas HbAS como HbSS (Iweala et al., 2010).

Uma das hipóteses que podem explicar a redução do número de células falciformes e a maior estabilidade das hemácias é através da atuação do extrato das sementes de guandu na diminuição da atividade da glutationa-S-transferase da hemácia (GST), uma enzima envolvida na remoção de xenobióticos circulantes, tais como agentes oxidantes (protoporfirina e ferro ${ }^{+3}$ ), os íons férricos e os superóxidos geradores de meta-hemoglobina, que facilitam a hemólise (Akinsulie et al., 2005).

A enzima GST da hemácia teria função protetora contra os compostos eletrofílicos e apresentaria alta atividade em pessoas com DF quando comparado aos indivíduos que não apresentam a doença (Uwakwe \& Ekeke, 1996; Onah et al. (2002).

No presente estudo de Uwakwe \& Ekeke (1996), esta redução da atividade enzimática foi maior no extrato de guandu (84\%) do que na fenilalanina $(59 \%)(p<0,05)$. Observaram correlação direta entre o tempo de consumo e o percentual de diminuição da atividade de GST, chegando ao final de três meses com o valor máximo de $74,9 \%$ $(p<0,05)$.

Concomitantemente, houve aumento na concentração de hemoglobina na ordem de cerca de $38 \%$ ao final de três meses $(p<0,05)$. Na Tabela 2 encontra-se uma síntese dos artigos científicos relacionando C. cajan e a DF.

\section{Toxicidade de C. Cajan}

Os estudos de toxicidade realizados com partes da planta como raiz, caule ou folhas, ou mesmo a semente não observaram nenhum efeito deletério nos animais e nos seres humanos (Shode \& Ekeke, 1985; Akinsulie et al., 2005). Porém, Torres et al. (2004) indicam que os polipeptídios do feijão guandu podem ter efeito alergênico ocasionando rinite e asma em pessoas susceptíveis.

No Brasil, há relato do uso do extrato de C.cajan juntamente com Acanthospermum hispidum para induzir o aborto. Lemonica \& Alvarenga (1994) testaram a infusão destas ervas na proporção (1: 1.3 respectivamente) em diferentes doses em ratas grávidas e, concluíram que houve má formações externas, que foram doses dependentes, e internas, que se caracterizavam por anomalias viscerais em fetos a termo.

Não foram encontrados estudos com seres humanos que demonstraram ser segura a oferta de C. cajan em mulheres grávidas. Apesar disso, os possíveis efeitos colaterais decorrentes dos efeitos tóxicos do feijão devem ser melhor estudados.

\section{DISCUSSÃO}

Os estudos apresentados nesta revisão demonstram a ação do feijão guandu na reversão da falcização e na promoção da estabilidade das hemácias com HbSS. Os resultados observados revelam a necessidade de elucidar melhor os mecanismos bioquímicos de como o feijão age na hemácia falciforme.

$\mathrm{Na}$ Nigéria o extrato aquoso da semente de C. Cajan tem sido formulado e administrado 
TABELA 2: Síntese de estudos científicos sobre C. cajan na DF publicado entre 1985-2010.

\begin{tabular}{|c|c|c|c|}
\hline Autor/origem/ano & Estudo & Características da Amostra & Princípios Ativos \\
\hline $\begin{array}{l}\text { Ekeke \& Shode Nigeria, } \\
1985\end{array}$ & In vitro & $\begin{array}{l}\text { Amostras de sangue de } 14 \text { indivíduos (HbSS) } \\
\text { com idades entre 11-25 anos }\end{array}$ & $\begin{array}{l}\text { Fitoquímicos no extrato do feijão } \\
\text { guandu }\end{array}$ \\
\hline $\begin{array}{l}\text { Iwu et al. } \\
1986\end{array}$ & In vitro & $\begin{array}{l}\text { Amostras de sangue de indivíduos (HbSS). } \\
\text { Idade não relatada. }\end{array}$ & $\begin{array}{l}\text { Fitoquímicos no extrato do feijão } \\
\text { guandu }\end{array}$ \\
\hline $\begin{array}{l}\text { Ekeke \& Shode Nigeria, } \\
1988\end{array}$ & In vitro & $\begin{array}{l}\text { Amostras de sangue de crianças (HbSS) com } \\
\text { idades entre 3-8 anos. }\end{array}$ & Fenilalanina \\
\hline $\begin{array}{l}\text { Iwu et al. } \\
\text { Nigéria, } 1988\end{array}$ & In vitro & $\begin{array}{l}\text { Amostras de sangue de } 5 \text { crianças com doença } \\
\text { falciforme de um hospital universitário. }\end{array}$ & Cajaminose \\
\hline $\begin{array}{l}\text { Akojie \& Fung Nigéria/ } \\
\text { USA, } 1992\end{array}$ & In vitro & $\begin{array}{l}\text { Amostras de sangue de } 2 \text { pacientes (HbSS), } \\
\text { com idades não relatadas. }\end{array}$ & $\begin{array}{l}\text { Fenilalanina } \\
\text { Ácido } p \text {-hidroxibenzóico } \\
\text { Fitoquímicos no extrato do feijão } \\
\text { guandu }\end{array}$ \\
\hline $\begin{array}{l}\text { Uwakwe et al. Nigéria, } \\
1996\end{array}$ & In vivo & 8 voluntários com HbSS. & $\begin{array}{l}\text { Fitoquímicos no extrato do feijão } \\
\text { guandu }\end{array}$ \\
\hline $\begin{array}{l}\text { Uwakwe \& Ekeke } \\
\text { Nigéria , } 1996\end{array}$ & In vitro & $\begin{array}{l}\text { Amostras de sangue de } 5 \text { voluntários (HbSS) } \\
\text { com idades entre 1-16 anos. }\end{array}$ & $\begin{array}{l}\text { Fenilalanina } \\
\text { Fitoquímicos no extrato do feijão } \\
\text { guandu }\end{array}$ \\
\hline $\begin{array}{l}\text { Onah et al. } \\
\text { Nigéria, } 2002\end{array}$ & In vitro & $\begin{array}{l}\text { Amostras de sangue de pacientes com idades } \\
\text { entre } 10-15 \text { anos. }\end{array}$ & $\begin{array}{l}\text { Fitoquímicos no extrato do feijão } \\
\text { guandu }\end{array}$ \\
\hline $\begin{array}{l}\text { Akinsulie et al. Nigéria, } \\
2005\end{array}$ & In vivo & $\begin{array}{l}42 \text { indivíduos (HbSS) com idades entre 1-15 } \\
\text { anos. }\end{array}$ & $\begin{array}{l}\text { Fenilalanina } \\
\text { Vitamina C } \\
\text { Zinco }\end{array}$ \\
\hline $\begin{array}{l}\text { Iweala et al. } \\
\text { Nigeria, } 2010\end{array}$ & In vitro & $\begin{array}{l}\text { Amostras de sangue de pacientes com } \mathrm{HbAA} \text {, } \\
\mathrm{HbAS} \text { e HbSS. }\end{array}$ & $\begin{array}{l}\text { Fitoquímicos no extrato do feijão } \\
\text { guandu }\end{array}$ \\
\hline
\end{tabular}

Fontes: fao, 1970; 'PINHEIRo Et Al., 2002; § PACHECO, 2006; ^philipp et al., 1999; \&USDA.

para pacientes com DF com melhora na frequência de crises álgicas (Onah et al., 2002; Ameh et al., 2012; Imaga, 2013). No Brasil, não há existência de pesquisas que avaliem o uso do feijão guandu nos pacientes com DF.

A fenilalanina foi apontada como o princípio ativo mais estudado que atuaria na reversão de hemácias falcizadas. Teixeira et al. (1985) estudaram o cultivar Kaki e observaram que o percentual de fenilalanina no tipo creme e alaranjado correspondia em média entre $11,53 \%$ na fração protéica e 2,66 $\%$ na matéria seca.

Outras leguminosas com quantidade importante de fenilalanina devem também ser investigadas como potenciais agentes de antifalcização. A Tabela 3 mostra o conteúdo de fenilalanina em várias leguminosas e suas respectivas medidas caseiras. Observa-se que o feijão guandu só perde em maior conteúdo de fenilalanina para a soja.

Portanto, a inclusão desta leguminosa na alimentação seria importante dada à quantidade expressiva de fenilalanina. De acordo com Canniatti-
Brazaca et al. (1996), os cultivares L04, L12 e L36 provavelmente possuiriam melhor introdução à alimentação humana, pois exibem produção elevada com curto período para a maturação dos grãos, menor tempo de cocção (próximo ao do feijão comum Phaseolus vulgaris) e maior conteúdo protéico. Os resultados observados revelam a necessidade de elucidar melhor os mecanismos bioquímicos de como o feijão age na hemácia falciforme.

\section{CONSIDERAÇÕES FINAIS}

Foi demonstrado em alguns estudos que a fenilalanina isolada tem menor efeito do que quando associada ao ácido p-hidroxibenzóico.

O sinergismo entre o ácido p-hidroxibenzóico e fenilalanina pode estar relacionado a redução da atividade de GST, devido a diminuição da concentração espécies reativas de oxigênio nas hemácias falciformes que consequentemente ajudam na inibição da falcização.

No entanto, estudos bioquímicos e fitoquímicos são necessários para identificar outros 
TABELA 3. Conteúdo de fenilalanina em algumas leguminosas.

\begin{tabular}{lll}
\hline Leguminosas & $\begin{array}{l}\text { Fenilalanina } \\
(\mathrm{mg} / 100 \mathrm{~g} \text { do alimento) }\end{array}$ & Medida Caseira \\
\hline Soja (Glycine max) & 2.055 & 2 1/3 colheres de servir ${ }^{\Delta}$ \\
Feijão Guandu (Cajanus cajan (L.) Millsp) & 1.727 & $2 / 3$ xícara de chá \\
Lentilha (Lens culinaris L.) & 1.266 & 1 concha média rasa* \\
Feijão comum (Phaseolus vulgaris L.) & 1.154 & 1 concha média * \\
Grão-de-bico (Cicer arietinum L.) & 1.151 & 5 colheres (sopa) cheias * \\
Ervilha (Pisum sativum) & 1.033 & 6 colheres(sopa) cheias $\$$ \\
\hline
\end{tabular}

compostos responsáveis e os mecanismos pelos quais o extrato da semente de guandu modifica o sistema metabólico e enzimático das hemácias nos pacientes com DF.

O estudo aprofundado do papel específico de $C$. cajan pode trazer benefícios ao prognóstico das pessoas com DF e, portanto, deve ser considerado.

\section{AGRADECIMENTOS}

Aos Professores Doutores Beatriz Vicente e Geraldo Castelar Pinheiro da Pós-Graduação em Ciências Médicas (PGCM/FCM/UERJ).

Ao Ministério da Saúde na pessoa da Doutora Joice de Jesus Aragão e do Doutor Paulo Ivo Cortez de Araújo.

\section{REFERÊNCIAS}

ABU, S.; ANYAIBE, S., HEADINGS, V. Chromatography fraction of anti-sickling agents in fagara xanthoxyloides. Acta haematologica, v.66, p. 19-26, 1981.

AFOLABI, I.S. et al. Solenostemon monostachyus, Ipomoea involucrata and Carica papaya seed oil versus Glutathione, or Vernonia amygdalina: methanolic extractsof novel plants for the management of sickle cell anemia disease. BMC Complement Alternative Medicine. v.22, p.1-11, 2012.

AKINSULIE, A.O. et al. Clinical evaluation of extract of Cajanus cajan (Ciklavit) in sickle cell anaemia. Journal Tropical Pediatrics. v. 51, n.4, p.200-5, 2005.

AKOJIE, F.O.; FUNG, L.W.; Antisickling activity of hydroxybenzoic acids in Cajanus cajan. Planta Medica, v.58, n.4, p.317-20, 1992 .

ARAUJO PIC. O autocuidado na doença falciforme. Revista Brasileira de Hematologia e Hemoterapia, v.29, n.3, p. 239-246, 2007.

AZEVEDO, R.L. et al. Abelhas (Hymenoptera: Apoidea) visitantes das flores do feijão guandu no Recôncavo Baiano. Revista do Centro de Ciências Rurais, v.37, n.5, p. 1453-1457, 2007.

BATISTA, A.; ANDRADE, T.C. Anemia falciforme: um problema de saúde pública no Brasil. Universistas Ciências da Saúde, v.3, n.1,p.83-99, 2008.

BRAGA, J.A.P. Medidas gerais no tratamento das doenças falciformes. Revista Brasileira de Hematologia e Hemoterapia, v.29, n.3, p.233-238, 2007.

BRASIL. Ministério da Saúde. Agência Nacional de Vigilância Sanitária. Manual de diagnóstico e tratamento de doenças falciformes. Brasília: ANVISA, 2001 a, p.142.

BRASIL. Ministério da Saúde. Secretaria de Atenção à Saúde. Departamento de Atenção Especializada. Manual de condutas básicas na doença falciforme. Ministério da Saúde, Secretaria de Atenção à Saúde, Departamento de Atenção Especializada. Brasília: Ministério da Saúde, Normas e Manuais Técnicos, p.56. (Série A), 2006.

BRUNIERA, P. Crise de sequestro esplênico na doença falciforme. Revista Brasileira de Hematologia e Hemoterapia, v.29, n.3, p. 259-261, 2007.

CANNIATTI-BRAZACA, S.G. et al. Avaliação física, química, bioquímica e agronômica de cultivares de feijão-guandu (cajanus cajan (I) mil). Alimentos e Nutrição Araraquara, v.7, n.1,37-45,1996.

CHOUGULE, N.P. et al. Differential inhibition of Helicoverpa armigera gut proteinases by proteinase inhibitors of pigeonpea (Cajanus cajan) and its wild relatives. Phytochemistry, v.64, n.3, p. 681-7, 2003.

CRUZ-GARCIA, G.S.; PRICE, L.L. Ethnobotanical investigation of 'wild' food plants used by rice farmers in Kalasin, Northeast Thailand. Journal of Ethnobiology and Ethnomedicine, v.7, n.33, p.1-20, 2011.

DAS, N. et al. Purification and characterization of urease from dehusked pigeonpea (Cajanus cajan L) seeds. Phytochemistry, v.61, n.5, p. 513-21, 2002.

DASH, B.P. et al. Search for antisickling agents from plants. Pharmacognosy Reviews. V.7, n13, p.53-60, 2013.

EKEKE, G.I.; SHODE, F.O. The Reversion of Sickled Cells by Cajanus cajan. Planta Medica, v.51, n.6, p.504-7, 1985.

EKEKE, G.I.; SHODE, F.O. Phenylalanine is the predominant agent in Cajanus cajan seed extract. Planta Medica, v.56, n.1, p.41-3, 1988.

EMOKPAE, M.A. et al. Correlation of oxidative stress and inflammatory markers with the severity of sickle cell nephropathy. Annals of African Medicine; v.9, p. 141-6, 2010.

FERREIRA, T.S. et al. Phytotherapy: an introduction to its history, use and application. Revista Brasileira de Plantas Medicinais; v.16, n.2, p.290-298, 2014.

FRANKLIN, I.M.; HUEHNS, E.R. The molecular basis of antisickling agents. Transactions of the Royal Society 
of Tropical Medicine and Hygiene. V.74, n.6, p.695700,1980

GALKIN, O. et al. Two-step mechanism of homogeneous nucleation of sickle cell hemoglobin polymers. Biophysical Journal. V.93, n.3: 902-13, 2007.

GIRI, A.P.; KACHOLE, M.S. Amylase inhibitors of pigeonpea (Cajanus cajan) seeds. Phytochemistry, v.47, n.2, p.197-202, 1998.

GODOY, R. et al. Caracterização de Onze Linhagens Puras de Guandu Selecionadas em São Carlos, SP.

Revista Brasileira de Zootecnia, v.33, n.6, p. 220613, 2004.

GODWIN, M.; BAYSINGER, M. Understanding antisickling agents and the sickling process. Nursing Clinics of North America. v.18, n.1, p.207-214, 1983.

HOFFBRAND, A.V.; MOSS, P.A.H. Distúrbios genéticos da hemoglobina. In: Fundamentos em Hematologia - 6a ed. Porto Alegre: Artmed, 2013 p.88-90.

IQBAL, Z. et al. Investigation of sickle-cell haemoglobin polymerization under electrochemical control.Physical Chemistry Chemical Physics Journal. v.14, n.10, p.2143 - 2148, 2013.

IWU, M.M. et al. Effect of cajaminose from Cajanus cajan on gelation and oxygen affinity of sickle cell haemoglobin. Journal of Ethnopharmacology. v.23, n.1, p.99-104, 1988.

JESUS, J.A. Doença Falciforme no Brasil. Gazeta Médica da Bahia, v.80, n.3, p.8-9, 2010.

LEMONICA, I.P.; ALVARENGA, C.M. Abortive and teratogenic effect of Acanthospermum hispidum DC. and Cajanus cajan (L.) Millps. in pregnant rats. Journal of Ethnopharmacology, v. 43, n.1, p.39-44, 1994.

LI, H.; LYKOTRAFITIS, G. A coarse-grain molecular dynamics model for sickle hemoglobin fibers. Journal of the Mechanical Behavior of Biomedical Materials. V.4, n.2, p.162-73, 2011.

LOBO, C. Doença falciforme - um grave problema de saúde pública mundial. Revista Brasileira de Hematologia e Hemoterapia, v.32, n.4, p.280-281, 2010.

MIZUBUTI, I.Y. et al. Propriedades funcionais da farinha e concentrado protéico de feijão guandu (Cajanus cajan (I.) Millsp). Archivos Latinoamericanos de Nutrición, v.50, n.3, p. 274-280, 2000.

MENEZES, J.B. et al. Modificações dos Componentes de Parede Celular do Melão Tipo Galia durante o armazenamento sob Refrigeração. Ciência e Tecnologia de Alimentos, v.17, n.3, p.42-49, 1997.

MODELL, B.; DARLISON, M. Global epidemiology of haemoglobin disorders and derived service indicators: Public health reviews. In: Bulletin of the World Health Organization (BLT), v.86, n.6, 480-487, 2008.

MUSKIET, F.A. et al. Supplementation of patients with homozygous sickle cell disease with zinc, a-tocopherol, vitamin C, soybean oil, and fish oil. The American Journal of Clinical Nutrition, v.54, p. 736-44,1991.

MEHANNA, A.S. Sickle cell anemia and antisickling agents then and now. Current Medicinal Chemistry. v.8, n.2, p.79-88, 2001.

NNAMANI, I.N.; et al. Pyridyl derivatives of benzaldehyde as potential antisickling agents. Chemistry \& Biodiversity. v.5,n.9, p.1762-1769, 2008.

NETO, G.C.G; PITOMBEIRA, M.S. Aspectos Moleculares da Anemia Falciforme. Jornal Brasileiro de Patologia e Medicina Laboratorial. v.39, n.1, p.51-53, 2003.

NAOUM, P.C. Interferentes Eritrocitários e Ambientais $\mathrm{Na}$ Anemia Falciforme. Revista Brasileira de Hematologia e Hemoterapia, v.22, n.1: p.05-022, 2000.

NWODO, U.U. et al. In vivo evaluation of the antiviral activity of Cajanus cajan on measles virus. Archives of Virology, v. 156, n.9, p.1551-7, 2011.

OLIVEIRA, L.A.R. et al. Levantamento sobre o uso de plantas medicinais com a terapêutica anticâncer por pacientes da Unidade Oncológica de Anápolis. Revista Brasileira de Plantas Medicinais, v.16, n.1, p.32-40, 2014.

ONAH, O.J. et al.The kinetics of reversal of pre-sickled erythrocytes by the aqueous extract of Cajanus cajan seeds. Phytotherapy Research Wiley Online Library, v.16, n.8, p. 748-50, 2002.

ONIYANGI, O.; COHALL, D.H. Phytomedicines (medicines derived from plants) for sickle cell disease. Cochrane Database Systematic Review, v.6, n.10, p.1-30 2013.

OUATTARA, B. et al. LC/MS/NMR analysis of isomeric divanilloylquinic acids from the root bark of Fagara zanthoxyloides Lam. Phytochemistry, v.65, n.8, p.114551, 2004.

OUATTARA, B. etal. Antisickling properties of divanilloylquinic acids isolated from Fagara zanthoxyloides Lam. (Rutaceae). Phytomedicine,v.16,n.2-3, p.125-9, 2009.

PACHECO, M. Tabela de Equivalentes, Medidas Caseiras e Composição Química Dos Alimentos. 2ª Ed., 2011. $688 p$.

PARK, S.; et al. Regioselective covalent modification of hemoglobin in search of antisickling agents. Journal of Medicinal Chemistry. v.46, n.6, p.936-953, 2003.

PROVAZI, M. et al. Descrição botânica de linhagens puras selecionadas de guandu. Revista Brasileira de Zootecnia, v.36, n.2, p. 328-34, 2007.

QUINN, N.L. et al. Genomic organization and evolution of the Atlantic salmon hemoglobin repertoire. BMC Genomics. v.11, n.539,p.1471-2164, 2010.

ROTTER, M. et al. Nucleation of sickle hemoglobin mixed with hemoglobin A: experimental and theoretical studies of hybrid-forming mixtures. Biophysical Journal. V.101, n.11, p.2790-2797, 2011.

ROSSATO, S.B. et al. Antioxidant potential of peels and fleshes of peaches from different cultivars. Journal of Medicinal Food, v.12, p. 1119-1126, 2009.

SANTOS, J.L.; CHIN, C.M. Anemia falciforme: desafios e avanços na busca de novos fármacos. Química Nova v. 35, n.4, p.783-790,2012.

SEGAL, J.B. et al. Concentrations of B vitamins and homocysteine in children with sickle cell anemia. Southern Medical Journal. v.97, n.2, p. 149-55. 2004.

SENO, M.S. et al. Caracterização do Material de reserva em feijão-guandu, lablale e mucuna. Bragantia, v.55, n.1, p.57-65, 1996.

SILVA, F.G.; OLIVEIRA, G.L.. Conhecimento popular e atividade antimicrobiana de Cydonia oblonga Miller (Rosaceae). Revista Brasileira de Plantas Medicinais, v.15, n.1, p.98-103, 2013.

TACO. Tabela de composição de alimentos. 4a. ed. rev. e ampl. Campinas: NEPAUNICAMP, 2011. 161 p.

TEIXEIRA, J.P.F. et al. Composição química de grãos 
de feijão-guandu cultivar kaki. Bragantia, v.44, n.1, p. 457-63,1985.

TORRES, M.C.L.; SOARES, N.F.F.; MAIA, J.F. Parâmetros cinéticos da Glutationa S-Transferase e sua ativação por extratos de vegetais. Ciência e Tecnologia dos Alimentos. v.24, n.2, p.243-248, 2004.

UZUNOVA, V. V. et al. Free heme and the polymerization of sickle cell hemoglobin. Biophysical Journal. v.99, n.6: p.1976-85., 2010.

USDA. Nutrient Data Laboratory. National Nutrient Database for Standard Reference. 2008, EUA. Disponível em: http://ndb.nal.usda.gov.. Acesso em 02 de julho de 2011.

UWAKWE, A.A.; EKEKE, G.I. Effects of the extract of Cajanus cajan seeds on HbSS erythrocyte
Glutathione-S-transferase activity. Nutrition Research, v.16, n.9, p.1459-65,1996.

VIEIRA, R.D.A. Composição de alguns vinhos orgânicos. 2010. 41p. Monografia (Tecnologia em viticultura e enologia). Secretaria de educação profissional e tecnológica Instituto Federal de Educação, Ciência e Tecnologia de Bento Gonçalves, RS.

ZAGO, M.A., PINTO, A.C.S. Fisiopatologia das doenças falciformes: da mutação genética à insuficiência de múltiplos órgãos. Revista Brasileira de Hematologia e Hemoterapia. V.29, n.3 p.207-214, 2007.

ZEMEL, B.S. et al. Effect of zinc supplementation on growth and body composition in children with sickle cell disease. The American Journal of Clinical Nutrition, v.75, n.2, p.300-7, 2002. 